Fibrin Glue for Better Success

\title{
ROLE OF FIBRIN GLUE FOR BETTER SUCCESS RATE IN MYRINGOPLASTY
}

\author{
Sohail Aslam, Adnan Asghar, Syed Muhammad Asad Shabbir Bukhari, Sunarays Akhtar, Humza Mumtaz, Muhammad Fahad Wasim
}

Pakistan Naval Ship Shifa Hospital, Karachi Pakistan

\section{ABSTRACT}

Objective: To see graft uptake success rate in platelet rich fibrin aided underlay myringoplasties using temporalis fascia graft compared to conventional underlay myringoplasties.

Study Design: Double blind randomized controlled trial study.

Place and Duration of Study: ENT department, Pakistan Naval Ship Shifa Hospital, from Jan to Jun 2019.

Methodology: Sixty cases with dry central tympanic membrane perforations were recruited. The patients suffering from sensori-neural hearing loss and co-morbidities like diabetes were excluded. The sampling technique was probability simple random. Patients were divided into two groups by lottery method. Statistical analysis was performed by using SPSS. The chi square test was applied to calculate $p$-value.

Results: Out of total 60 patients 38 were males and 22 were females. Study group's (Fibrin) mean age was $31.77 \pm 12.43$ years and Control group's mean age was $27.53 \pm 11.41$ years. All the patients in platelet rich fibrin group had successful graft uptake at 2 months follow-up. In control group with conventional technique 23 out of 30 patients had successful graft uptake and rest 7 patients had different issues leading to graft rejection.

Conclusion: In under lay myringoplasty procedure, application of platelet rich fibrin on temporalis fascia graft edge and perforation edges has significantly improved the successful uptake rate of graft.

Keywords: Myringoplasty, Platelet rich fibrin, Temporal fascia graft.

How to Cite This Article: Aslam S, Asghar A, Bukhari SMAS, Akhtar S, Mumtaz H, Wasim NF. Role of Fibrin Glue for Better Success Rate In Myringoplasty. Pak Armed Forces Med J 2021; 71 (Suppl-3): S603-606. Doi: https://doi.org/10.51253/pafmj.v1i1.4298

\footnotetext{
This is an Open Access article distributed under the terms of the Creative Commons Attribution License (https://creativecommons.org/licenses/by-nc/4.0/), which permits unrestricted use, distribution, and reproduction in any medium, provided the original work is properly cited.
}

\section{INTRODUCTION}

Prevalence of chronic supportive otitis media in developing countries is quite high from $4-11 \%$. Central perforation is commonly seen in both tubotympanic and atticoantral disease. For tubotympanic disease, myringoplasty is routinely done for perforated tympanic membrane repair. It is the most accepted surgical procedure used to repair perforation in safe types of chronic suppurative otitic media (central pars tensa perforations). Among the list of graft materials used in myringroplasty autologous temporalis fascia has shown most satisfactory results in terms of successful uptake. Both techniques (overlay and underlay) of myringoplasty achieve satisfactory results, with the underlay technique being slightly better than the overlay technique. Therefore, underlay technique being technically simple should be preferred, but the ultimate decision about the technique to be employed depends on the surgeons preference and the site of perforation. ${ }^{1}$ Another factor was the choice of graft materials used for myringoplasties. Temporalis fascia has been widely used for decades. A latest study confirms that the tem-

Correspondence: Dr Sohail Aslam, Classified ENT Specialist, Pakistan Naval Ship Shifa Hospital, Karachi Pakistan poralis graft is better than conchal perichondrial graft for closure of perforations in inactive mucosal type of chronic otitis media with a central perforation. The post-operative results showed that hearing improvement was better in the study group receiving temporalis fascia as graft material than the group receiving conchal perichondrium. ${ }^{2}$ Graft uptake results vary because of multiple factors. Graft lateralization, residual perforation, re perforation and failure of vascularization of grafts have been witnessed quite often. Strauss studied use of human tissue adhesive in guinea pigs in 1984. Human fibrin tissue adhesive diminished the rate of recurrent perforations in tympanoplastic on a statistical base $(n=1051){ }^{3}$ To enhance wound healing, platelet concentrates are being used in many centers of the world with promising outcomes. Hence, the use of platelet-rich fibrin in ear surgeries would also improve the tympanic membrane healing. Many centers around the world have attempted use of fibrin glue in tympanoplaty. ${ }^{4,5}$ Fibrin Glue is prepared from platelet-rich plasma or by mixing concentrated fibrinogen solutions with thrombin. ${ }^{6}$

The aim of our study is to see graft uptake success rate in platelet rich fibrin aided underlay myringoplasties using temporalis fascia graft compared to conventional underlay myringoplasties. 


\section{METHODOLOGY}

This was a, carried out at ENT department, Pakistan Naval Ship Shifa Hospital, from January to June 2019. This study has the approval of Hospital, bioethical committee and reference number was ERC 03 dated 06-4-2020. The prevalence of chronic suppurative ototis media tubotympanic disease is $4 \%$ in our region. The prevalence based WHO formula for sample size was applied which calculated 59 and we took 60 cases. The sixty cases with dry central tympanic membrane perforations were recruited after proper informed written consent. All the perforations were involving 3 or 4 quadrants of pars tensa. All the patients were above the age of 15 and had conductive deafness without any infection or suspicion of cholesteatoma. The patients suffering from sensori-neural hearing loss, traumatic brain injuries, tinnitus, co-morbidities like diabetes or hypertension and known allergy to any drug or chemical biological materials were excluded from the study.

The sampling technique was probability simple random. Patients were divided into two groups by lottery method, so that neither patient nor operating surgeon was aware of group allocation. Patient's demographic data was collected in a performa and allocated group was mentioned. Both study and control groups having 30 patients underwent myringoplasty. Myringoplasty in all patients was performed by postaural approach, using under lay technique while temporalis fascia was used as graft in each surgery. In study group, we prepared platelet rich fibrin from each patient's blood by using centrifuge machine, which was used as plug over temporalis fascia graft and tympanic membrane remnant to seal perforation. In control group, gel foam was kept over sealed perforation, Wound closure, in both group, was done in two layers while external auditory canal was packed by BIPP dressing. All the surgeries were performed by one senior ENT surgeon.

Post operatively, ear packing was removed after one week. Otomicroscopy and graft uptake was assessed at 2 weeks and then 2 months after surgery. Pure tone audiometry was carried out first before surgery and then after 2 months of surgery. A healed tympanic membrane, lateralization of graft, anterior blunting or graft refection was analyzed for comparison between two groups postoperatively. Final result was confirmed using oto-microscopy by a blinded observer (ENT consultant).
Statistical analysis was performed for the demographic data of patients' gender, age and distribution of left and right ears between two groups. $p$-value of less than 0.05 was considered to be the statistically significant so that confounding effect of these variables was analyzed. For the data of ages of patients, means and standard deviations of both groups calculated and independent sample t-test was applied to check the statistical difference between two groups. The distribution of left and right ears between two groups was also assessed by chi-square test for the statistical difference. The main outcome variable of graft uptake at 2 months after surgery was compared between two groups by applying chi-square test to see whether statistically significant difference is observed to prove the study group being more successful.

\section{RESULTS}

Out of total 60 patients 38 were males and 22 were females. The difference of gender distribution between two groups was not statistically significant ( $p$-value 0.754 by pearson chi square test). As for as age is concerned, study group's (Fibrin) mean age was $31.77 \pm 12.43$ years and control group's (Conventional) mean age was $27.53 \pm 11.41$ years. The difference between ages of both groups was not found to be statistically different when analyzed by using independent sample t-test ( $p$-value 0.587$)$. In study group (Fibrin) there were 17 right ears and 13 left ears. While in control group (conventional) 14 right and 16 left ears were operated. The difference of this random distribution was also analyzed by applying pearson chi-square test and the difference was found to be not significant ( $p$ value 0.438 ).

All the patients in study group in whom platelet rich fibrin was utilized had successful graft uptake at 2 months follow-up (confirmed on otomicroscopy by a blind observer). While in control group with conventional technique without use of fibrin 23 out of 30 patients had successful graft uptake and rest 7 patients had different issues leading to graft rejection (partial or complete), as seen in Figure.

Four patients had graft rejection, two had anterior blunting while one patient had lateralization of graft. This difference was analy-zed by chi-square test and it proved that the difference was statistically significant (Pearson chi-square test $p$-value 0.005, Fisher's exact test $p$-value 0.011). 


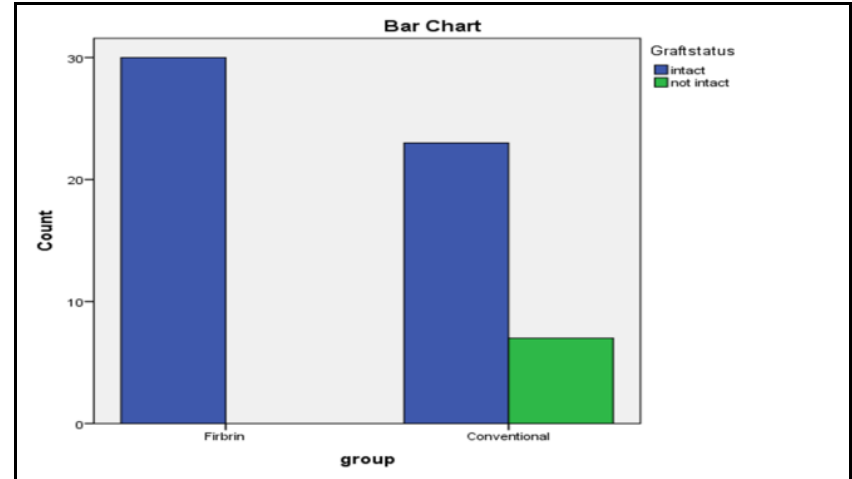

Figure: Results of two groups in terms of intact grafts.

Table: Comparison of successful percentage of graft uptake using fibrin in various studies

\begin{tabular}{l|c|c|c|c|c}
\hline Author & Year & $\mathbf{n}$ & $\begin{array}{c}\% \\
\text { Success }\end{array}$ & $\begin{array}{c}\text { Follow- } \\
\text { up }\end{array}$ & $\begin{array}{c}p \text { - } \\
\text { value }\end{array}$ \\
\hline Gur O & 2016 & 60 & $80 \%$ & 10 days & $<0.05$ \\
\hline Habesoglu M & 2012 & 32 & $64.3 \%$ & 1 month & $<0.05$ \\
\hline El-Anwar M & 2015 & 64 & $100 \%$ & 6 months & 0.02 \\
\hline Nair A & 2019 & 86 & $97.7 \%$ & 3 months & 0.012 \\
\hline Gokse Kutuk & 2019 & 55 & $94.4 \%$ & 6 months & 0.031 \\
\hline This study & 2019 & 60 & $100 \%$ & 2 months & 0.011 \\
\hline
\end{tabular}

\section{DISCUSSION}

This study was compared to other similar studies and summarized in the table. Gur et al, evaluated results of platelet rich fibrin membrane using recovery rates, healing time and reduction of mean air bone gap as indicators in patients with closure of traumatic perforation of ear drums. The comparison of these outcomes was also made with results in patients undergoing paper patch technique using of platelet rich fibrin membrane with regard to same indicators mentioned earlier. ${ }^{7}$ Jabesoglu at Umraniye Hospital, investigated the results of Choukroun"s platelet rich fibrin (PRF) on traumatic ear drum perforation of recent onset without relying on traditional myringoplasty techniques. Results at one month were more in favour of study group (PRF) while at two months post operatively, the difference between two groups was not statistically significant $(p>0.05)$. He found that platelet rich fibrin (PRF) in autogenous, useable and quite simple to fix biomaterial which enhances tympanic membrane healing process. ${ }^{8}$ El-Anwar et al assessed the topical use of autologous platelet rich plasma (PRP) to improve success rate of myringoplasty in 2015. After assessing results at 6 months, it was concluded that topical autologous PRP application during myringolpasty is safe and highly efficient and successful with no reported complication. PRP not only enhances healing of chronic TM perforations but also avoids infection and obviates the need for inner EAC pack. ${ }^{9}$ The compa- rison in various studies is shown in Table-I. Similarly Nair A observed eighty six patients over two years and wrapped up after making comparison between the groups that being autologous material, platelet rich fibrin is harmless for patients.

The postoperative graft uptake rate is better in cases in which platelet-rich fibrin was used. The postoperative infection rate was also lower in the same group. ${ }^{10}$

Gokse Kutuk evaluated the inference of platelet rich fibrin treatment on graft uptake and frequency specific squeal of hearing thresholds in myringoplasty was evaluated by Gokse Kutuk ${ }^{11}$. According to him, platelet rich fibrin aided temporalis fasia graft survival rates showed more revealing results at one, three and six monthly follow up visit than procedure done using temporalis fascia alone. However, Meaningful distinctiveness was not observed in hearing thresholds gain between two groups. ${ }^{11}$ Our study on 60 patients also proved that platelet rich fibrin when used along with temporalis fascia, produced significantly better results compared to temporalis fascia alone.

Kumar et al conducted a pilot study amongst selected 25 patients with central perforations. All 25 patients underwent PTA assessment \& TCA $(50 \%)$ and autologous platelet rich fibrin (PRF) Plug Myringoplasty technique done and followed up to 6 months postoperatively. From this study, the closure rate in traumatic tympanic membrane perforation by TCA (50\%) and PRF Plug Myringoplasty technique was 92\% with statistically significant hearing improvement (88\%). ${ }^{12}$ Isono et al, used a small amount of fibrin glue and dripped onto the lateral margin of the perforation. They found that this technique can be used not only for small perforations, but also for large perforations which lack a posterior margin or total perforations of the membrane. ${ }^{13}$ Sankaranarayanan proved that platelet rich plasma is a cheap and cost effective platelet concentrate with enriched growth factors. It accelerates the tympanic membrane closure following myringoplasty. ${ }^{14}$ Zohar found this material useful in few other head and neck surgeries. This tissue adhesive system was used for coating and sealing during tympanoplasty, and for closure of perilymphatic fistulas, chylous fistulas, oral and pharyngeal fistulas, cerebrospinal fluid leaks, facial nerve injury, and in split-thickness skin graft and local skin flap application in hereditary hemorrhagic telangiectasia. Tissue glue is valuable in tissue repair and local hemostasis, facilitates the surgeon's work and may obviate more complicated surgi- 
cal procedures..$^{15}$ Soft tissue healing depicted much better results in experimented group using pain scoring scale while no significant destructive we was observed in bony tissue healing between two groups. ${ }^{16}$ PRF was shown to improve soft tissue generation and limit dimensional changes post-extraction in dentistry. ${ }^{17}$ Platelet rich pleasure is the most commonly used name among the platelet concentrates being used in many surgical procedures. However, this term has reacted mystifications in scientific database being so gerund and in complete. Dohan Ehrenfest et al, finalized these terminologies. They told that four main categories of products can be easily defined, depending on their leukocyte content and fibrin architecture: Pure PlateletRich Plasma (P-PRP), such as cell separator PRP, Vivostat PRF or Anitua's PRGF; Leukocyteand Platelet-Rich Plasma (L-PRP), such as Curasan, Regen, Plateltex, Smart PReP, PCCS, Magellan, Angel or GPS PRP; Pure Plaletet-Rich Fibrin ( $p$-PRF), such as Fibrinet; and Leukocyte- and Platelet-Rich Fibrin (L-PRF), such as Choukroun's PRF. P-PRP and L-PRP refer to the unactivated liquid form of these products, their activated versions being respectively named P-PRP gels and LPRP gels. ${ }^{18}$

It is pertinent to say that these newly developed platelet concentrates need comparative assessments by more meaningful trials. All the surgeries where soft tissue healing and vascularization is crucial to produce acceptable results, such products must be tried with the consent of patients as well as regulatory authorities. Similarly, more clinical trials to see efficacy of PRF on temporalis fascia graft myringoplasty are required using bigger sample size and long term post-operative follow up.

\section{CONCLUSION}

In under lay myringoplasty procedure, application of platelet rich fibrin on temporalis fascia graft edge and perforation edges has significantly improved the successful uptake rate of graft.

\section{Conflict of Interest: None.}

\section{Authors' Contribution}

SA: Corresponding, article writing, AA: Data collection, SMASB: Literature search, AAG: Data collection, SA: Literature search, HM: Data collection.

\section{REFERENCES}

1. Kalsotra P, Gupta R, Gupta N, Kotwal S, Suri A, Kanotra S. Overlay versus underlay myringoplasty: a comparative study. Ind J Otol 2014; 20(4): 183-188.

2. Sridhara Narayanan D, Vijay Kumar B, Hari PM. Comparative study of graft materials used in myringoplasty. J Pharm Sci Res 2016; 8(12): 1339-1342.

3. Strauss P, Pult P, Kurzeja A, Isselstein M, Mach P. Does human fibrin tissue adhesive improve the results of tympanoplasty? Laryngol Rhinol Otol 1984; 63(12): 615-617.

4. Fujino K, Ito J, Ota K, Tokuda Y. Fibrin Glue in Tympanoplasty. Pract Otorhinolaryngol (Basel). 1992; 6(1): 28-30.

5. Frank R, Stange G. Fibrin sealing in tympanoplasty. In: Neurosurgery Ophthalmic Surg ENT 1994; 57(5): 371-379.

6. Silver FH, Wang MC, Pins GD. Preparation and use of fibrin glue in surgery. Biomaterials. 1995; 16(12): 891-903.

7. Gür ÖE, Ensari N, Öztürk MT, Boztepe OF, Gün T, Selçuk ÖT, et al. Use of a platelet-rich fibrin membrane to repair traumatic tympanic membrane perforations: a comparative study. Acta Otolaryngol 2016; 136(10): 1017-1023.

8. Habesoglu M, Oysu C, Sahin S, Sahin-Yilmaz A, Korkmaz D, Tosun A. Platelet-rich fibrin for the repair of tympanic membrane. Otolaryngol Neck Surg 2012; 147(Suppl-2): P218-P218.

9. El-Anwar MW, El-Ahl MAS, Zidan AA, Yacoup MARAS. Topical use of autologous platelet rich plasma in myringoplasty. Auris Nasus Larynx 2015; 42(5): 365-368.

10. Nair NP, Alexander A, Abhishekh B, Hegde JS, Ganesan S, Saxena SK. Safety and efficacy of autologous platelet-rich fibrin on graft uptake in myringoplasty: a randomized controlled trial. Int Arch Otorhinolaryngol 2019; 23(1): 77-82.

11. Gökçe Kütük S, Özdaş T. Impact of platelet-rich fibrin therapy in tympanoplasty type 1 surgery on graft survival and frequency -specific hearing outcomes: A retrospective analysis in patients with tympanic membrane perforation due to chronic otitis media. J Laryngol Otol 2019; 133(12): 1068-1073.

12. Kumar RD. Application of Platelet Rich Fibrin Matrix to Repair Traumatic Tympanic Membrane Perforations: A Pilot Study Ind J Otolaryngol Head Neck Surg 2019; 71(Suppl-2): 1126-1134.

13. Isono M, Fukuyama $Y$, Murata K. Tympanic membrane perforations closed with fibrin glue. Pract Otol 1993; 28(5): 913-932.

14. Sankaranarayanan G, Prithiviraj V, Kumar R. A study on efficacy of autologous platelet rich plasma in myringoplasty. Otolaryngol Online J 2013; 3(3): 1-3.

15. Zohar Y, Shwilli Y, Schimberg R, Buler N. Human fibrin glue in head and neck surgery. Harefuah 1994; 126(10): 567-70.

16. Kumar YR, Mohanty S, Verma M, Kaur RR. Platelet-rich fibrin: The benefits. Br J Oral Maxillofac Surg 2016; 54(1): 57-61.

17. Miron RJ, Zucchelli G, Pikos MA, Salama M, Lee S. Use of platelet-rich fibrin in regenerative dentistry: a systematic review. Clin Oral Investig 2017; 21(6): 1913-1927.

18. M. Dohan Ehrenfest D, Bielecki T, Mishra A, Borzini P, Inchingolo F, Sammartino G, et al. In search of a consensus terminology in the field of platelet concentrates for surgical use: platelet-rich plasma (PRP), platelet-rich fibrin (PRF), fibrin gel polymerization and leukocytes. Curr Pharm Biotechnol 2012; 21(6): 1913-1927. 